\title{
A simple method to create superhydrophobic aluminium surfaces
}

\author{
R. Jafari ${ }^{a}$ and M. Farzaneh ${ }^{b}$ \\ NSERC / Hydro-Quebec / UQAC Industrial Chair on Atmospheric Icing of Power Network Equipment \\ (CIGELE) and Canada Research Chair on Atmospheric Icing of Power Network Equipment (INGIVRE), \\ www.cigele.ca \\ Université du Québec à Chicoutimi, Chicoutimi, QC, Canada \\ arjafari@uqac.ca, ${ }^{\mathrm{b}}$ masoud_farzaneh@uqac.ca
}

\begin{abstract}
Superhydrophobic surfaces were prepared using a very simple and low-cost method by spray coating. A high static water contact angle of about $154^{\circ}$ was obtained by deposition of stearic acid on an aluminium alloy. However, this coating demonstrated a high contact angle hysteresis $\left(\sim 30^{\circ}\right)$. On the other hand, superhydrophobic surfaces with a static contact angle of about $162^{\circ}$ and $158^{\circ}$, and a low contact angle hysteresis of about $3^{\circ}$ and $5^{\circ}$ were respectively obtained by incorporating nanoparticles of $\mathrm{SiO}_{2}$ and $\mathrm{CaCO}_{3}$ in stearic acid. The excellent resulting hydrophobicity is attributed to the synergistic effects of micro/nanoroughness and low surface energy. A study of the wettability of these surfaces at temperatures ranging from 20 to $-10{ }^{\circ} \mathrm{C}$ showed that the superhydrophobic surface becomes rather hydrophobic at supercool temperatures.
\end{abstract}

\section{Keywords}

Superhydrophobicity, spray coating, stearic acid, $\mathrm{SiO}_{2}$ nanoparticles, aluminium

\section{Introduction}

Superhydrophobic surfaces (water contact angle $\theta>150^{\circ}$ ) with a low contact angle hysteresis have many potential industrial applications such as reduction of ice and snow adhesion, surface selfcleaning, stain resistant textiles, corrosion prevention and antibiofouling surfaces [1-2]. It is well known that the maximum contact angle that can be attained on a flat surface by lowering the surface energy does not exceed $120^{\circ}$. However, the addition of roughness to the surface can increase the contact angle of water without altering the surface chemistry [3]. Superhydrophobic surfaces can be achieved by a combination of low surface energy materials, and surface micro and nanostructures. The majority of these approaches start by creating the roughness on the surface, by means like chemical etching, plasma treatment, electrochemical method, template method, vapor deposition and sol-gel method and ends up with deposition of low surface energy materials on roughed surfaces [4-9]. The commonly used reactive molecules for low surface-energy modification are mainly long alkyl chain thiols, alkyl or fluorinated organic silanes, perfluorinated alkyl agents, long alkyl chain fatty acids, polydimethylsiloxane-based polymers or other polymers, or their combinations [6]. However, most of the chemicals materials used for hydrophobization are nonbiodegradable, expensive and potentially harmful to human health and the environment which limits their potential applications [10]. Therefore, developing a simple, inexpensive approach to obtain an industrially feasible superhydrophobic surface is important and necessary [11, 12]. The present study investigates a very simple, one-step and low-cost superhydrophobic coating prepared by spray coating of different nanoparticles in stearic acid on aluminium surfaces.

\section{Experimental set-up}

Polished 6061 aluminium alloy coupons $(2.54 \mathrm{~cm} \times 2.54 \mathrm{~cm} \times 0.15 \mathrm{~cm})$ from Rio Tinto Alcan: $\mathrm{Mg}$ 1.0, Si 0.6, $\mathrm{Cu} 0.28, \mathrm{Cr} 0.05, \mathrm{Zn} 0.1, \mathrm{Fe} 0.25$ and $\mathrm{Mn} 0.15$ (all in wt \%) were used as the substrate. Prior to spray coating, the coupons were degreased using acetone, and then rinsed carefully with 
deionized water for 5 min each. The stearic acid (purity $>98 \%$ ) and $\mathrm{CaCO}_{3}$ (diameter $\sim 500 \mathrm{~nm}$ ), $\mathrm{SiO}_{2}$ (diameter $\sim 500 \mathrm{~nm}$ ) nanoparticles were obtained from Alfa Aesar. One g of stearic acid was dissolved in $50 \mathrm{ml}$ of acetone with a magnetic stirrer at $600 \mathrm{rpm}$ for 20 minutes at $30{ }^{\circ} \mathrm{C}$. An optimized concentration $(0.1 \mathrm{~g})$ of $\mathrm{CaCO}_{3}$ or $\mathrm{SiO}_{2}$ nanoparticles was dispersed in stearic acid by ultrasonication followed by magnetical stirring for about $15 \mathrm{~min}$ till a homogenous mixture was obtained. Then the precursor mixture was transferred to a spray gun and sprayed onto clean aluminium coupons at an optimized distance $(25 \mathrm{~cm})$. The coating was dried at room temperature in air overnight.

FT-IR spectra were measured on a Fourier transformation infrared spectrometer (Perkin-Elmer, Spectrum one). The reflected beam was collected for 24 scans at a resolution of $4 \mathrm{~cm}^{-1}$. Polished aluminium alloy was used as the reference. Sample surface morphology was examined using a LEO field emission scanning electron microscope (FESEM). Water contact angle measurements were carried out using a Kruss DSA 100 goniometer (water drop volume $\sim 4 \mu \mathrm{L}$ ). The static contact angle were acquired by fitting the symmetric water drops using the Laplace-Young method, which is theoretically considered to be the most accurate because it takes into account the distorted drop shape due to liquid weight. In order to measure the contact angle hysteresis, which is the difference between the advancing and receding contact angles, a commonly used experimental procedure was followed [9]. The advancing and receding contact angles were measured by holding the water drop with a stationary needle in contact with the surface. The substrate was moved slowly in one direction using a micrometric screw.

\section{Results and discussion}

Figure 1 shows FE-SEM images of a stearic acid coating deposited on the aluminium alloy surface. The presence of an uneven petal structure can be observed with pore diameters ranging from 200 to $900 \mathrm{~nm}$ and fibber length from $500 \mathrm{~nm}$ to several micrometers (Fig. 1b), resulting in a rough surface with porous structure.
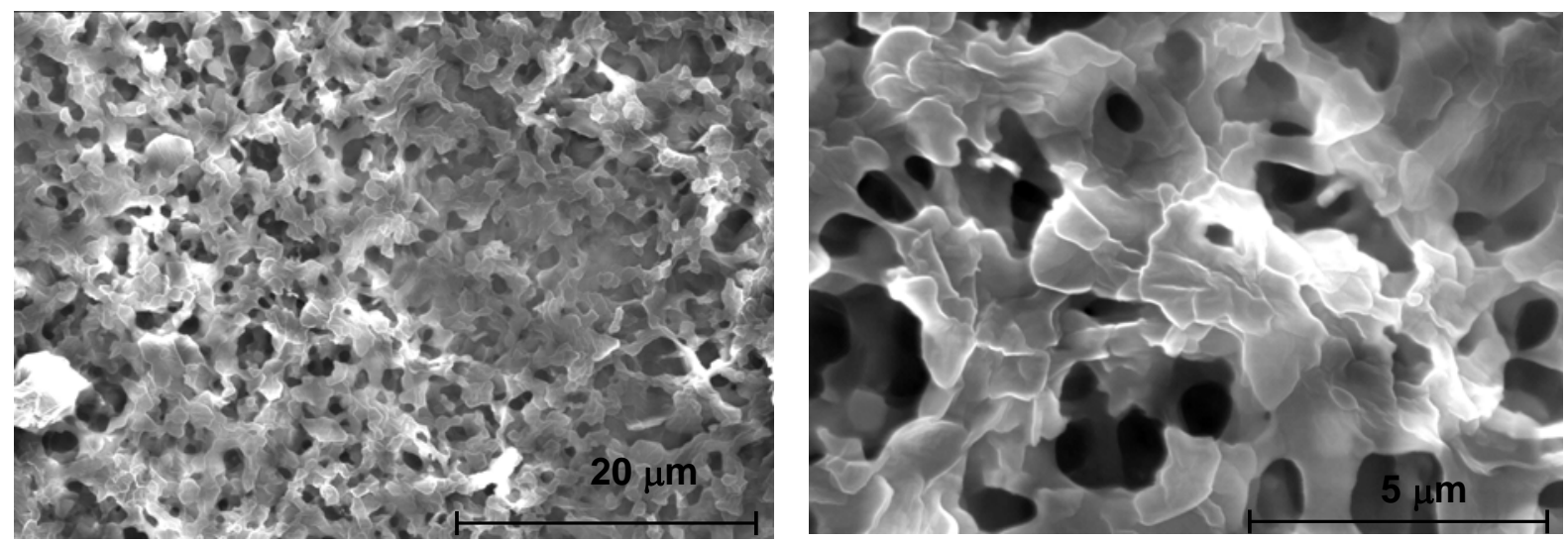

Figure 1: Scanning electron microscopy images of stearic acid coating deposited on aluminium alloy surface (a) low magnification image (b) magnified image

In Fig. 2, the reflection absorption infrared spectrum of the stearic acid coating on aluminium substrate is displayed. Both the asymmetric $\left(v_{\text {as }}\left(\mathrm{CH}_{2}\right)\right)$ and symmetric $\left(\mathrm{v}_{\mathrm{s}}\left(\mathrm{CH}_{2}\right)\right)$ methylene stretching peaks clearly appear at 2921 and $2851 \mathrm{~cm}^{-1}$, respectively [13], with the peak at $2951 \mathrm{~cm}^{-}$ 1 , arising from asymmetric $\mathrm{CH}_{3}$ stretching [14]. Also, the so-called progressional bands that arise from the $\mathrm{CH}$ wagging and twisting vibrations in the $1150-1350 \mathrm{~cm}^{-1}$ region can be seen. The $\mathrm{C}=\mathrm{O}$ stretching peak and the $\mathrm{C}-\mathrm{O}$ stretching plus the $\mathrm{O}-\mathrm{H}$ deformation band appear at $1698 \mathrm{~cm}^{-1}$ and $1430 \mathrm{~cm}^{-1}$, respectively. These show the presence of $-\mathrm{CH}_{3}$ and $-\mathrm{CH}_{2}$ groups on the deposited stearic 
acid coating, which can reduce the surface energy and provide the resulting surface with hydrophobic properties.

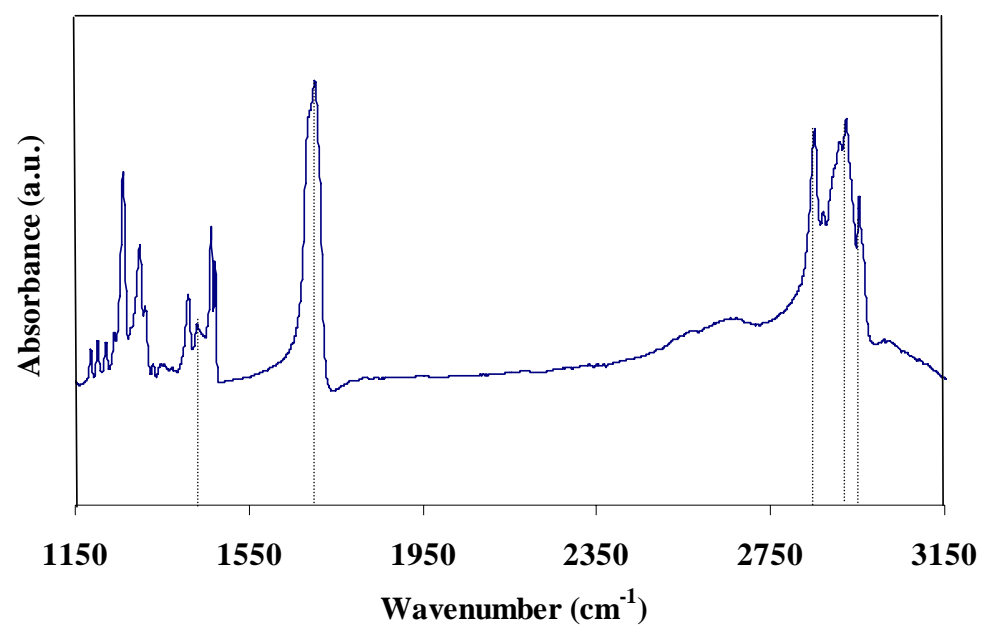

Figure 2: FTIR spectra from stearic acid coating deposited on aluminium alloy surface

The water contact angle of the prepared superhydrophobic surface was examined. The results showed that the static contact angle $(\theta \mathrm{s})$ increases from $88^{\circ}$ for the polished aluminium surface to $154^{\circ}$ for stearic acid coating deposited on the polished aluminium surface. The dynamic behaviour of water droplets on superhudrophobic surfaces is of great importance in applications such as icephobic coating. For instance, a high contact angle water droplet deposited on a horizontal surface may remain pinned until the surface is tilted to a considerable angle [15]. The contact angle hysteresis $(\mathrm{CAH})$ measurements showed a high $\mathrm{CAH}$ value of about $30^{\circ}$ for the stearic coatings deposited on the aluminium surface.

There are the two main models that attempt to describe the wetting of textured surfaces, the Wenzel and Cassie-Baxter models [16]. In the Wenzel model (homogenous interface), the roughness can increase the area of liquid-solid interface and the adhesion between them is strong. In the Cassie-Baxter model (composite interface), air (or gas) pockets are trapped in the rough surface cavities, resulting in a composite solid-liquid-air interface, as opposed to the homogeneous solid-liquid interface. Due to the small solid-liquid contact area in the Cassie-Baxter state, the hysteresis is very small and a liquid drop can roll off easily. Therefore, these results (high static contact angle and $\mathrm{CAH}$ ) showed that a homogeneous interface (Wenzel state) was formed between the acid coating and the water droplet. It is well known that the static and hysteresis contact angles are influenced by surface roughness [17]. In order to increase the static contact angle and decrease the $\mathrm{CAH}$ of stearic acid coatings, $\mathrm{CaCO}_{3}$ and $\mathrm{SiO}_{2}$ nanoparticles were incorporated into the stearic acid. Figure 3 shows the hierarchical morphology in composite coating such as these nanoparticlestearic acid coatings. In Figure 3, for each nanoparticle case, two images with increasing magnifications (from left to right) are shown. Figures 3a-3b are images of coatings with $\mathrm{SiO}_{2}$ nanoparticles in stearic acid and Figs. $3 \mathrm{c}-3 \mathrm{~d}$ are those with $\mathrm{CaCO}_{3}$ nanoparticles. The presence of $\mathrm{SiO}_{2}$ nanoparticles in the stearic acid coating can be observed in Fig. 3a, with a magnified image in Fig. 3b. It was also observed that silica nanoparticles were well distributed, which can generate nanoscale roughness. Figures $3 \mathrm{c}-3 \mathrm{~d}$ show the formation of a foam-like coating structure on stearic acid- $\mathrm{CaCO}_{3}$ nanoparticle surface for which there is a remarkable change in the surface morphology. This change in morphology features is probably be due to the formation of carbonate stearate bicarbonate on the surface $[18,19]$. 

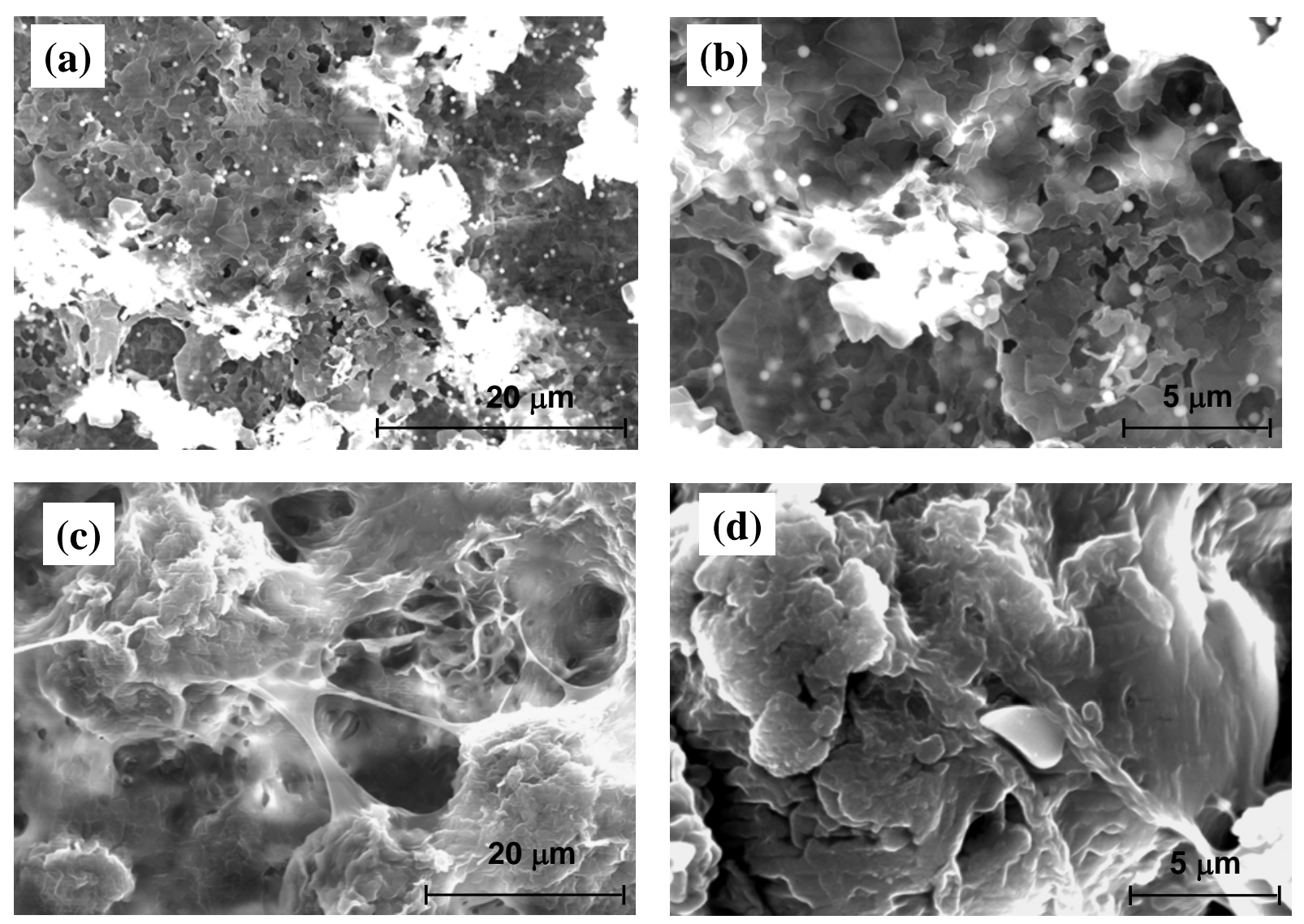

Figure 3: Scanning electron microscopy images of a stearic acid- $\mathrm{SiO}_{2}$ coating: (a) low magnification image (b) magnified image; stearic acid- $\mathrm{CaCO}_{3}$ coatings (c) low magnification image (d) magnified image

The results of static contact angle and contact angle hysteresis measurements for various coatings are presented in Table 1. They show that by incorporating $\mathrm{SiO}_{2}$ or $\mathrm{CaCO}_{3}$ nanoparticles in stearic acid coatings, a small increase in static contact angle and a high decrease in CAH were obtained. The clear distinction between the $\mathrm{CAH}$ values for the stearic acid coatings alone as compared to those with incorporated $\mathrm{CaCO}_{3}$ or $\mathrm{SiO}_{2}$ nanoparticles can be explained in terms of a transition between the Wenzel state (droplet supported on the asperities of the rough surface with air trapped underneath) and the Cassie-Baxter state (liquid penetrates the asperities of the substrate) [20].

Table 1: Static contact angles and contact angle hysteresis of different coatings

\begin{tabular}{|c|c|c|c|}
\hline Coating type & Stearic acid & Stearic acid $+\mathrm{SiO}_{2}$ & Stearic acid $+\mathrm{CaCO}_{3}$ \\
\hline Static contact angle $\left(\theta^{\circ}\right)$ & 154 & 160 & 158 \\
\hline Contact angle hysteresis $\left(\theta^{\circ}\right)$ & 30 & 3 & 4 \\
\hline
\end{tabular}

The study of the wettability of superhydrophobic surfaces at supercooled temperature is of prime importance for the development of icephobic coatings [21, 22]. So, the contact angle measurements of samples were carried out at low temperatures. For this purpose, a Kruss DSA 100 apparatus was fitted with a Peltier cooling element permitting lowering the substrate temperature down to $-30{ }^{\circ} \mathrm{C}$. The results showed that the superhydrophobic surface became rather hydrophobic as the surface 
temperature went down from $20{ }^{\circ} \mathrm{C}$ to $-10{ }^{\circ} \mathrm{C}$. However, the decrease was more pronounced for superhydrophobic surfaces with higher CAH (Table 2).

Table 2: Variation of static contact angles of stearic acid and stearic acid- $\mathrm{SiO}_{2}$ coating as a function of temperature

\begin{tabular}{|c|c|c|c|c|c|}
\hline Temperature $\left({ }^{\circ} \mathrm{C}\right)$ & 20 & 5 & 0 & -5 & -10 \\
\hline Contact angle of Stearic acid coating $\left(\theta^{\circ}\right)$ & 154 & 140 & 134 & 129 & 120 \\
\hline Contact angle of Stearic acid $+\mathrm{SiO}_{2}$ coating $\left(\theta^{\circ}\right)$ & 160 & 152 & 148 & 138 & 133 \\
\hline
\end{tabular}

In fact, when the rough surfaces are exposed to temperatures lower than zero, condensed water penetrates into the porosities of the coating and the water vapour condensation leads to a so-called Cassie-Wenzel regime transition resulting in lower contact angles [21]. This phenomenon seems be more important for surfaces with higher $\mathrm{CAH}$ because of the higher water penetration in the rough surface cavities which can increase the surface contact with the supercooled surface.

\section{Conclusion}

A simple and low cost technique was proposed for making superhydrophobic coatings by spray coating a mixture of $\mathrm{SiO}_{2}$ or $\mathrm{CaCO}_{3}$ nanoparticles incorporated in stearic acid. SEM images show the presence of micro/nanostructures on the resulting superhydrophobic surfaces. FTIR analyses of the stearic acid coating showed the presence of $\mathrm{CH}_{3}$ and $\mathrm{CH}_{2}$ groups, which contribute the low surface energy of the coating. The addition of $\mathrm{SiO}_{2}$ or $\mathrm{CaCO}_{3}$ nanoparticles to the stearic acid coating allowed a substantial decrease in contact angle hysteresis from $30^{\circ}$ to $3^{\circ}$ and $4^{\circ}$ for $\mathrm{SiO}_{2}$ and $\mathrm{CaCO}_{3}$ respectively and a small increase in the static contact angle from $154^{\circ}$ to $158^{\circ}$ and $162^{\circ}$, respectively. Study of wettability at low temperature showed that the resulting superhydrophobic surfaces become rather hydrophobic with descending surface temperature from 20 to $-10{ }^{\circ} \mathrm{C}$. However, this reduction is more pronounced for superhydrophobic surfaces with higher $\mathrm{CAH}$. The advantages of the present approach are that it uses fluorine-free raw materials and environmentally benign solvents, it is industrially implementable method, and easy to use which give it great potential for application.

\section{Acknowledgements}

This work was carried out within the framework of the NSERC/Hydro-Quebec/UQAC Industrial Chair on Atmospheric Icing of Power Network Equipment (CIGELE) and the Canada Research Chair on Engineering of Power Network Atmospheric Icing (INGIVRE) at Université du Québec à Chicoutimi. The authors would like to thank the CIGELE partners (Hydro-Québec, Hydro One, Réseau Transport d'Électricité (RTE) and Électricité de France (EDF), Alcan Cable, K-Line Insulators, Tyco Electronics, Dual-ADE, and FUQAC) whose financial support made this research possible. The authors also wish to thank Hélène Grégoire (National Research Council Canada, ATC, Saguenay) for SEM analysis.

\section{References}

[1] Z. Guo, W. Liu, B.-L Su, Journal of Colloid and Interface Science 353 (2010), p. 335.

[2] H. Chen, Z. Yuan, J. Zhang, Y. Liu, K. Li, D. Zhao, S. Li, P. Shi, J. Tang, , J Porous Mater vol 16 (2009), p. 447. 
[3] X-M. Li, D. Reinhoudt, M.C. Calama, Chem. Soc. Rev. 36 (2007), p. 1350.

[4] Zhang X., Shi F., Niu J., Jiang Y., Wang Z., J. Mater. Chem. 18 (2008), p. 621.

[5] R. Jafari and M. Farzaneh, Applied Physics A, 102 (2011), p. 195.

[6] C.-H, Xue, S.-T. Jia, J. Zhang, J.-Z. Ma, Sci. Technol. Adv. Mater. 11 (2010), 033002.

[7] G. Momen, M. Farzaneh, R. Jafari, Applied Surface Science (in press)

[8] Ma M., Hill R. M., Curr. Opin. Colloid Interface Sci. 11 (2006), p.193.

[9] R. Jafari, R. Menini and M. Farzaneh, Applied Surface Science, 257 (2010), p. 1540.

[10] T. Bahners, T. Textor, K. Opwis, E. Schollmeyer, Journal of Adhesion Science and Technology 22 (2008), p.285.

[11] B. Balu, V. Breedveld, D.W. Hess, Langmuir, 24 (2008), p. 4785.

[12] B. Yin, L. Fanga, J. Hu, A.-Q. Tang, W.-H. Wei, J. He, Applied Surface Science 257 (2010), p. 1666.

[13] S. Ren, S. Yang, Y. Zhao, T. Yu, X. Xiao, Surface Science 546 (2003), p. 64.

[14] S.J. Lee, K. Kim, Vibrational Spectroscopy 18 (1998), p.187.

[15] D. Kim, W. Hwang, H.C. Park, K.-H. Lee, Current Applied Physics 8, (2008), p. 770.

[16] M. Nosonovsky, B. Bhushan, Multiscale Dissipative echanisms and Hierarchical Surfaces, Verlag Berlin Heidelberg : Springer, 2008

[17] P.G. de Gennes, , Rev. Mod. Phys. 57 (1985), p. 827.

[18] Z. Hu, X. Zen, J. Gong, Y. Deng, Colloids and Surfaces A: Physicochem. Eng. Aspects 351 (2009), p. 65.

[19] X. Shi, R. Rosa, A. Lazzeri, Langmuir, 26 (2010), p. 8474.

[20] M.K. Tiwari, I.S. Bayer, G.M. Jursich, T.M. Schutzius, C.M. Megaridis, Applied materials and letters, 2 (2010), p.1114.

[21] L. Yin, Q. Xia, J. Xue, S. Yang, Q. Wang, Q. Chen, Appl. Surf. Sci. 256 (2010), p. 6764.

[22] R. Karmouch, G.G. Ross, J. Phys. Chem. C 114 (2010), p. 4063. 